\title{
Rectourinary Fistula after Radical Prostatectomy: Review of the Literature for Incidence, Etiology, and Management
}

\author{
Hiroshi Kitamura and Taiji Tsukamoto \\ Department of Urology, Sapporo Medical University School of Medicine, South 1 West 16, Chuo-ku, Sapporo 060-8543, Japan \\ Correspondence should be addressed to Hiroshi Kitamura, hkitamu@sapmed.ac.jp
}

Received 27 October 2010; Revised 10 December 2010; Accepted 7 January 2011

Academic Editor: J. W. Moul

Copyright ( 2011 H. Kitamura and T. Tsukamoto. This is an open access article distributed under the Creative Commons Attribution License, which permits unrestricted use, distribution, and reproduction in any medium, provided the original work is properly cited.

\begin{abstract}
Although rectourinary fistula (RUF) after radical prostatectomy (RP) is rare, it is an important issue impairing the quality of life of patients. If the RUF does not spontaneously close after colostomy, surgical closure should be considered. However, there is no standard approach and no consensus in the literature. A National Center for Biotechnology Information (NVBI) PubMed search for relevant articles published between 1995 and December 2010 was performed using the medical subject headings "radical prostatectomy" and "fistula." Articles relevant to the treatment of RUF were retained. RUF developed in $0.6 \%$ to $9 \%$ of patients after RP. Most cases required colostomy, but more than $50 \%$ of them needed surgical fistula closure thereafter. The York-Mason technique is the most common approach, and closure using a broad-based flap of rectal mucosa is recommended after excision of the RUF. New techniques using a sealant or glue are developing, but further successful reports are needed.
\end{abstract}

\section{Introduction}

Radical prostatectomy (RP) is a common treatment for patients with clinically organ-confined prostate cancer. RP is associated with complications such as urinary incontinence, erectile dysfunction, and rectal injury. Since the standardization of the anatomic retropubic RP (RRP), optimization of the surgical technique has been pursued with the purpose of reducing complications [1].

A rectourinary fistula (RUF) is an abnormal opening between the rectum and the bladder or the urethra that results in fecaluria, pneumaturia, and drainage of urine per anus. RUF is a rare but major complication of RP [2]. Management has been traditionally based on urinary or fecal diversion in the hope of spontaneous closure [3], but most of the patients require surgical closure even after such diversions, which means that urinary or fecal diversions tend to be preparatory maneuvers prior to surgical repair. Although surgical approaches, including perineal, transrectal, transsphincteric, and transanorectal repairs are well known, there is no standardized treatment for RUF because of its low prevalence. In this paper, we focus on the incidence and treatment of RUF after RP, and the minimally invasive and most promising treatments are also highlighted and discussed.

\section{Incidence and Diagnosis of RUF after RP}

Rectal injury during RP is one of the main etiologies of RUF. It can occur during apical dissection while attempting to develop the plane between the rectum and Denonvilliers' fascia [4]. Previous series of community-based practice demonstrated $1.5 \%$ to $2.2 \%$ incidences of rectal injury during radical retropubic prostatectomy (RRP), and $0.6 \%$ to $9 \%$ of the cases were finally diagnosed as RUF [5-7]. RUF can appear after RP, even if there is no finding of rectal injury during the operation. In the series of 689 RRP 
and 59 cystoprostatectomies of Noldus et al. [8], 25 rectal injuries occurred. Although 23 of them were diagnosed intraoperatively and closed, RUF developed in 13 patients thereafter [8]. Thomas et al. [9] reported that a third of patients with RUF experienced rectal injury during RRP, which was closed in 2 layers immediately. RUF mostly develops a few weeks after RP, but the range of days is quite wide [10].

There are four surgical options for removing the prostate, $\mathrm{RRP}$, radical perineal prostatectomy (RPP), laparoscopic RP (LRP), and robot-assisted laparoscopic RP (RALP). Comparative studies of LRP versus RRP [11-17], RALP versus RRP [18-20], and LRP versus RALP [21] demonstrated that the incidences of rectal injury in RRP, LRP, and RALP were $0 \%$ to $3 \%, 0 \%$ to $2.8 \%$, and $0 \%$ to $0.15 \%$, respectively. The incidences of RUF in RPP were reported to be 1 to $1.5 \%$ $[9,22,23]$. No study showed a significant difference in the prevalence of rectal injury for any RP procedure, except for a retrospective one [9], which demonstrated that the risk of RUF was 3.06-fold higher for RPP versus RRP. Thus, RUF can occur after any RP technique.

Diagnosis of RUF is not difficult. The clinical presentation of RUF depends on the size of the fistula. Patients usually complain of fecaluria and/or pneumaturia and also watery stool. Fecaluria seems to be a poor prognostic sign [9]. Whatever the clinical symptoms, retrograde urethrocystography, urethrocystoscopy, and rectoscopy or colonoscopy are essential to determine the best management strategy $[10,24]$.

\section{Impact of Prior Prostate Radiation on RUF after RP}

Radiotherapy-induced cystitis, fibrosis, and tissue plane obliteration are factors that can lead to rectal injuries [25]. A retrospective study from Cleveland Clinic [26] reviewed 22 patients with prostate cancer who were managed with radiation-induced RUF. Six patients were treated with brachytherapy (BT) alone, 5 with external beam radiation therapy (EBRT) alone, 10 with BT + EBRT, and 1 with RP + salvage EBRT [26]. Successful RUF closure was achieved in 9 patients, but 4 of them underwent proctectomy [26]. In a series between 1977 and 2002 from the Mayo Clinic, RUF after EBRT, BT, and EBRT + BT occurred in 30\%, 30\%, and $40 \%$, respectively [27]. A prospective study from UCSF reported that 7 of 16 patients with RUF underwent prior RP and the other 9 had been treated with BT, EBRT, or cryotherapy [2]. Thus, RUF can be caused by radiotherapy alone.

Therefore, prostate radiation prior to RP is a risk factor for RUF. The incidence of rectal injury after salvage prostatectomy ranges from $2 \%$ to $15 \%$ [25]. Gotto et al. [28] reported that RUF developed in $22 \%$ of men with rectal injury and in $2 \%$ of those without it in the salvage prostatectomy group and in $0 \%$ of men with it and $0.06 \%$ of those without it in the RP group. There was a significant association between rectal injury and subsequent RUF after salvage prostatectomy but not after RP. Although the population of such patients is unique, the difficulty of management for the subsequent RUF with low success rates at surgical repair should be taken into account.

\section{Conservative Approach}

There are few successful reports of conservative management of RUF, which indicates the therapeutic limitations of this approach. In the series of 1447 RP of Thomas et al. [9], three of 13 patients with RUF were treated conservatively without colostomy or surgical closure. These patients showed no fecaluria, and the fistula closed spontaneously during transurethral catheterization after 28 to 100 days [9].

If the RUF is not closed after 3 months of catheterization, further treatment should be considered. The second step of treatment for RUF is fecal diversion. Colostomy was performed for patients with RUF for initial management in a series from the Mayo Clinic, but all of these patients required definitive surgical intervention because of the lack of spontaneous closure [29]. Thomas et al. [9] reported that $33 \%$ of patients who underwent colostomy and insertion of a transurethral catheter displayed spontaneous closure of the RUF 23 to 99 days after colostomy. Thus, fecal diversion does not always result in spontaneous closure. For patients without closure at 3 months after fecal diversion, the next step, surgical closure, is recommended. The timing of surgical closure advocated is 2 to 3 months after colostomy $[9,30]$, since the tissue should be allowed to restore itself for 2 to 3 months prior to fistula repair [31]. If the surgical closure provides a promising result like a very low anterior resection for rectal cancer, loop ileostomy can also be considered for fecal diversion. For the treatment of RUF, however, colostomy seems to be preferred, since it is still a challenging procedure. Thus there has been only one report [32] in which ileostomy was performed with Soave's procedure.

\section{Surgical Treatment Methods}

5.1. Approach. Various approaches, including transperineal, transanal, posterior pararectal, transabdominal and transvesical, transsphincteric, and combined ones [10], have been reported for RUF. If an omental or gluteal muscle flap is planned for closure of the RUF, the transperineal approach is mandatory. However, this approach should be considered only when the fistula is located between the rectum and urethra anterior to the prostate (recto- "urethral" fistula), because the space is too small to expose and repair RUF superior to the pubic bone. It can also be technically difficult because of scar tissue and has been associated with urinary incontinence and urinary stricture [33]. The transsphincteric (York-Mason) and the transsacral (Kraske) approaches, providing excellent exposure, are preferable and often chosen these days. The procedures are described in Table 1. Since RUF occurs at the low rectum, the York-Mason procedure is sufficient to expose the operative field around the RUF in most cases. Moreover, the morbidity of the Kraske procedure is greater than that for the York-Mason one. From $15 \%$ to $25 \%$ of patients who undergo the Kraske procedure develop rectocutaneous fistula [34], whereas $5 \%$ to $7 \%$ do 

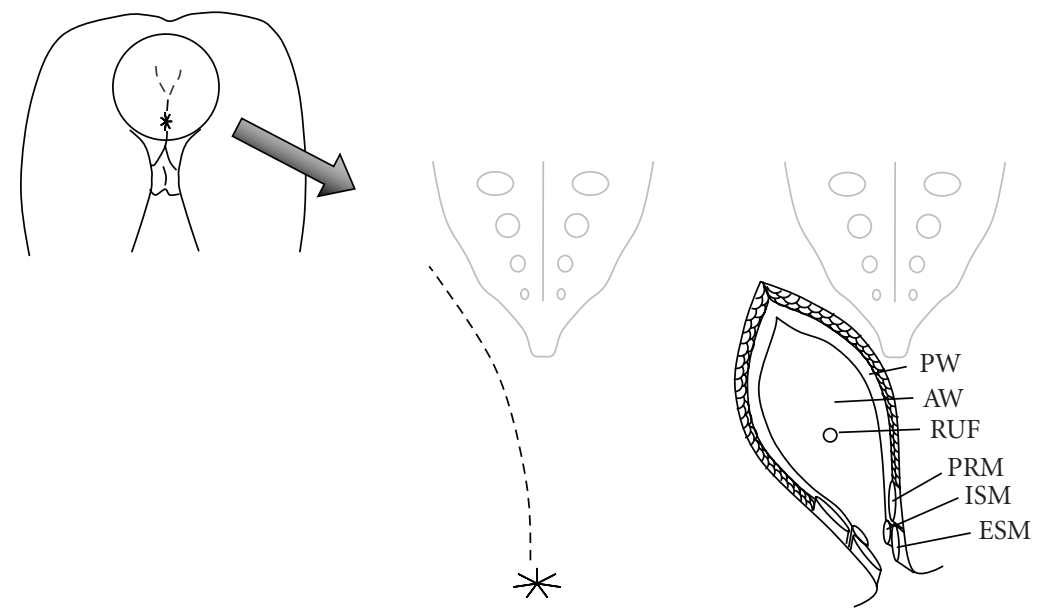

FIGURE 1: The York-Mason technique. PW: posterior wall of the rectum; AW: anterior wall of the rectum; RUF: rectourinary fistula; PRM: puborectal muscle; ISM: internal sphincter muscle; ESM: external sphincter muscle.

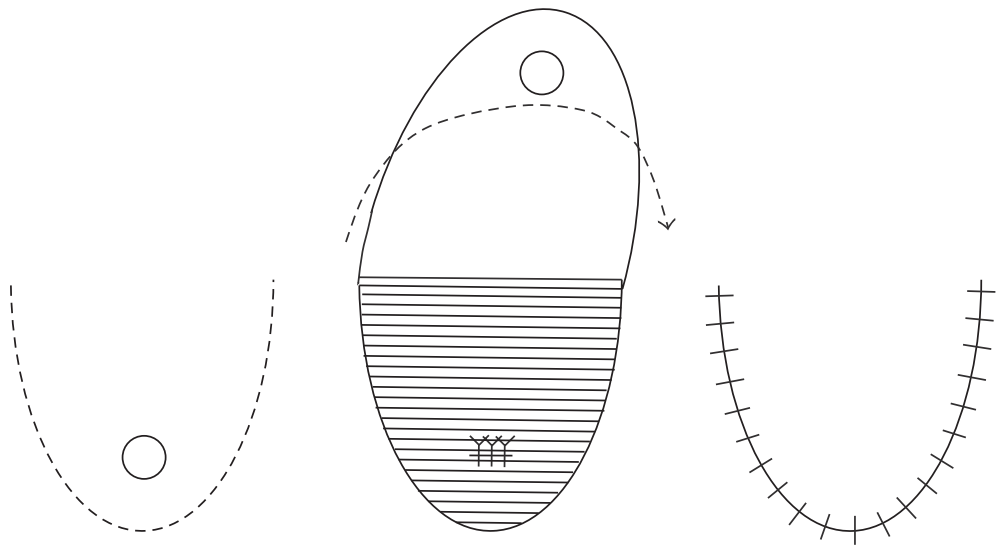

FIgURE 2: Rectal advancement flap [3].

after the York-Mason [24] procedure. Thus the York-Mason approach is considered the most appropriate procedure with minimal morbidity (Figure 1). The largest study using this approach, reported by Renschler and Middleton [35], contributed the majority of knowledge about the management of RUF. In the York-Mason procedure, however, layered closure of the anal sphincter is mandatory not only to avoid the risk of fistula but also to maintain fecal continence [10]. The external and internal sphincters and puborectal muscles should be separately demarcated by stay sutures for better identification during closure.

5.2. Technique of RUF Closure. After exposure of the anterior surface of the rectal wall, the RUF is usually resected with a wide margin. Then the bladder or urethral defect is closed with absorbable interrupted sutures in one layer. If the RUF is in the urethra, the sutures should be performed in a transverse fashion to avoid urethral stricture [10]. There are several procedures for closure of the rectal defect. Although simple layer-to-layer closure seems to be effective, the rectal flap method can prevent recurrence of the RUF at the suture site (Figure 2). Of the rectal flap methods, the Latzko technique may provide the most promising outcome. This procedure was developed for vesicovaginal fistula with a high success rate [59] and applied to RUF by Noldus et al. [8]. To prevent recurrence of RUF, it is important not only to close the fistula in a layer-to-layer fashion but also to eliminate the possibility of contact between the urinary and rectal mucosae.

A major alternative technique to prevent recurrent RUF is gracilis muscle interposition. The gracilis is the most superficial muscle on the medial side of the thigh, arising from the symphysis pubis and inferior pubic ramus [44]. After a perineal skin incision, dissection at the RUF, and closure of the RUF in 2 layers, the gracilis muscle is harvested, rotated, and placed into the anterior perineal space with fixation about $3 \mathrm{~cm}$ above the RUF site [30, 42-45]. This technique provides a high success rate and is one of the most promising treatments for RUF. Recently, Spahn et al. [41] reported 5 patients with RUF who underwent buccal mucosa graft interposition with successful closure, although more cases should be included to validate the result. 
TABLE 1: Posterior approaches to RUF.

\begin{tabular}{lll}
\hline & York-Mason & Kraske \\
\hline $\begin{array}{l}\text { Approach } \\
\text { Position }\end{array}$ & Transsphincteric prone jackknife & Transsacral prone jackknife \\
\hline & $\begin{array}{l}\text { (1) Incision from the sacrococcygeal articulation to the } \\
\text { anal verge } \\
\text { (2) } \begin{array}{l}\text { Transection of entire sphincter complex in a } \\
\text { layer-by-layer fashion }\end{array}\end{array}$ & (1) Paracoccygeal incision 2-10 cm from the anal verge \\
Procedure & $\begin{array}{l}\text { (3) Pairs of marking sutures at the mucocutaneous } \\
\text { junction for resuture }\end{array}$ & (3) Resection of S4, S5, and coccyx \\
& $\begin{array}{l}\text { (4) Midline division of the mucosa of the anus and the } \\
\text { full thickness of the posterior rectal wall }\end{array}$ & (4) Midline division of the Waldeyer's fascia \\
\hline (5) Sleeve resection or proctotomy & (5) Sleeve resection or proctotomy
\end{tabular}

Although there have been few studies of RUF repairs that compared the outcomes of nonradiating fistulas with radiating ones, Vanni et al. [60] recently reported the largest experience of a total of 74 patients. RUF repairs with an anterior perineal approach and muscle interposition flap were performed with success rates of $100 \%$ and $84 \%$ in nonradiating and radiating cases, respectively. From the results of several studies $[26,27,60]$, the muscle interposition flap is considered the most promising method. However, some patients need aggressive treatments such as fecal and urinary diversions with proctectomy [26].

5.3. Endoscopic, Laparoscopic, and Robotic Repairs. Minimally invasive approaches, including endoscopic, laparoscopic, and robotic ones, are under development. There were 3 reports [50-52] of transanal endoscopic microsurgery. This technique needs a large endorectal microscope with a suction/irrigation channel and 3 working channels, as well as specially designed scissors, forceps, and needle folders. However, there have been only 5 cases reported in the literature [50-52]. Sotelo et al. performed laparoscopic and robotic repairs of RUF after RP for one patient each [54, 55, 61 . Both patients had a rectovesical fistula, and interposition of the omentum on the rectal sutures was carried out. The laparoscopic and robotic techniques provided successful closure of the RUF. These techniques are feasible, but special devices and technical skills are required.

\section{New Approaches Using Sealant or Glue}

Verriello et al. [62] reported the successful use of a commercial fibrin sealant (Quixil) in combination with an anterior mucosal flap for treatment of RUF. The fistula was healed without recurrence at 1-year followup. Fibrin sealant injection has been used in anal and rectovaginal fistulas with an approximately $70 \%$ success rate $[63,64]$. However, a prospective randomized trial for transsphincteric anal fistulae comparing fibrin glue treatment with seton treatment demonstrated that fibrin glue treatment had a significantly inferior probability of success [65]. Further successful cases using this procedure should be reported to confirm the excellent result.

Another method with cyanoacrylate glue was also reported. Bardari et al. [66] treated a patient with a neobladder-urethral fistula after radical cystoprostatectomy. They performed endoscopic application of cyanoacrylate glue, and the patient was disease free with no recurrence of RUF at a followup of 5 months. Bhandari et al. [67] also reported a successful case of a patient with RUF after RP. The patient was followed up 9 months after catheter removal without rectal leakage of urine. Although Bardari et al. [66] reported excellent results for this method of treatment of a prostate-perineal fistula after suprapubic prostatectomy and a neobladder-ileal fistula after radical cystoprostatectomy, further cases are necessary to validate those results.

Thus these approaches using a sealant or glue are not yet mainstays of treatment for RUF.

\section{Treatment for Recurrent RUF}

There have been few reports of treatment for recurrence after RUF repair. Some infill, for example, an omental or gluteus muscle flap, fibrin glue, and so forth, can be considered. Alternatively, the coloanal sleeve anastomosis (Soave procedure) can be selected. The Soave technique was originally developed for treatment of Hircshsprung's disease [68]. Chirica et al. [58] reported its application for RUF treatment after RP with a $100 \%$ cure rate. The left colon is transected, and rectal mucosectomy is completed to the level of the RUF and via a perineal approach from the dentate line. After externally closing the urinary fistula (if possible), the stapled colon is delivered to the anus. Then the colon is transected at the level of the dentate line, and a coloanal anastomosis is performed. Although this procedure is more invasive, it may be the ultimate treatment option for complex RUF [58].

However, recurrent RUF is the most challenging problem. Kasraeian et al. [40] reported 3 patients who required multiple York-Mason procedures without a significant increase of intraoperative or postoperative morbidity. They also suggested that a second or third operation 
TABLE 2: Contemporary reports of RUF repair after RP.

\begin{tabular}{|c|c|c|c|c|c|c|}
\hline Investigator & Year & Pts* $^{*}(n)$ & Approach & Graft/infill & Closure technique & $\begin{array}{l}\text { Success } \\
\text { rate }(\%)\end{array}$ \\
\hline Pera et al. [36] & 2008 & 5 & York-Mason & - & Layer-to-layer & 100 \\
\hline Crippa et al. [37] & 2007 & 5 & York-Mason & - & Layer-to-layer & 100 \\
\hline Dafnis et al. [38] & 2004 & 1 & York-Mason & - & Layer-to-layer & 100 \\
\hline Boushey et al. [39] & 1998 & 2 & York-Mason & - & Layer-to-layer & 100 \\
\hline dal Moro et al. [10] & 2006 & 4 & York-Mason & - & Layer-to-layer & 100 \\
\hline $\begin{array}{l}\text { Renschler and Middleton } \\
\text { [35] }\end{array}$ & 2003 & 13 & York-Mason & - & Layer-to-layer & 100 \\
\hline Kasraeian et al. [40] & 2009 & 12 & Modified York-Mason & - & $\begin{array}{l}\text { Layer-to-layer (only } \\
\text { anterior rectal wall) }\end{array}$ & 100 \\
\hline Spahn et al. [41] & 2009 & 4 & Transperineal & Buccal mucosa & Mucosal patch & 75 \\
\hline Zmora et al. [42] & 2006 & 2 & Transperineal & $\begin{array}{l}\text { Gracilis muscle } \\
\text { flap }\end{array}$ & Layer-to-layer & 100 \\
\hline Rivera et al. [43] & 2007 & 6 & $\begin{array}{l}\text { Modified York-Mason } \\
\text { or transperineal }\end{array}$ & $\begin{array}{l}\text { — or gracilis } \\
\text { muscle flap }\end{array}$ & $\begin{array}{l}\text { Rectal flap or } \\
\text { layer-to-layer }\end{array}$ & 100 \\
\hline Ghoniem et al. [44] & 2008 & 10 & Transperineal & $\begin{array}{l}\text { Gracilis muscle } \\
\text { flap }\end{array}$ & Rectal flap & 100 \\
\hline Ulrich et al. [45] & 2009 & 4 & Transperineal & $\begin{array}{l}\text { Gracilis muscle } \\
\text { flap }\end{array}$ & Layer-to-layer & 100 \\
\hline Culkin and Ramsey [46] & 2003 & 3 & Transperineal & $\begin{array}{l}\text { Deepithelialized } \\
\text { scrotal flap }\end{array}$ & Y-V plasty & 100 \\
\hline Quazza et al. [47] & 2009 & 2 & Transperineal & $\begin{array}{l}\text { Omental flap } \\
\text { mobilized } \\
\text { laparoscopically }\end{array}$ & Layer-to-layer & 100 \\
\hline Youseff et al. [48] & 1999 & 2 & Transperineal & $\begin{array}{l}\text { Dartos pedicled } \\
\text { flap }\end{array}$ & Layer-to-layer & 100 \\
\hline Visser et al. [49] & 2002 & 3 & Transperineal & - & Rectal flap & 100 \\
\hline $\begin{array}{l}\text { Bochove-Overgaauw et al. } \\
\text { [50] }\end{array}$ & 2006 & 2 & Transanal endoscopic & - & Layer-to-layer & 50 \\
\hline Quinlan et al. [51] & 2005 & 1 & Transanal endoscopic & - & Layer-to-layer & 100 \\
\hline Wilbert et al. [52] & 1996 & 2 & Transanal endoscopic & Fibrin glue & Layer-to-layer & 100 \\
\hline Hata et al. [53] & 2002 & 1 & Transanal & - & Rectal flap & 100 \\
\hline Noldus et al. [8] & 1999 & 5 & Transanal & - & Latzko & 100 \\
\hline Joshi et al. [3] & 2010 & 4 & Transanal & - & Rectal flap & 100 \\
\hline Sotelo et al. [54] & 2005 & 1 & Laparoscopic & Omental flap & Layer-to-layer & 100 \\
\hline Sotelo et al. [55] & 2008 & 1 & Robotic & Omental flap & Layer-to-layer & 100 \\
\hline Abdalla [56] & 2009 & 1 & $\begin{array}{l}\text { Posterior sagittal } \\
\text { pararectal with rectal } \\
\text { mobilization }\end{array}$ & $\begin{array}{l}\text { Gluteus muscle } \\
\text { flap }\end{array}$ & Layer-to-layer & 100 \\
\hline Castillo et al. [57] & 2006 & 3 & $\begin{array}{l}\text { Anterior, transanal, } \\
\text { transsphincteric, } \\
\text { sagittal approach }\end{array}$ & - & Layer-to-layer & 100 \\
\hline Chirica et al. [58] & 2006 & 4 & $\begin{array}{l}\text { Intraperitoneal and } \\
\text { perineal }\end{array}$ & Omental flap & Soave & 100 \\
\hline
\end{tabular}

* Patients who underwent radical prostatectomy.

should be performed more than 5 months after the previous surgery. In general, repeated surgical failures can increase mortality and morbidity. Patients with nonrepairable RUF for whom prior attempts have failed should be considered for permanent urinary and fecal diversion. The options include cystoprostatectomy with an ileal conduit and proctectomy with continuation of the current fecal diversion.

\section{Conclusions}

Most of the techniques seem to provide high success rates (Table 2). The rectal flap method with the York-Mason approach and the gracilis muscle flap interposition are considered the most common procedures with high success rates and minimal morbidity. For radiated cases, gracilis muscle interposition may be preferred. However, since 
there has been no randomized clinical trial comparing the procedures because of the rarity of RUF, the best method is still unknown. The success of any surgical treatment assumes knowledge of all possible treatment methods. Recurrent or radiated RUF is the most challenging problem and sometimes requires permanent urinary and fecal diversion with proctectomy.

\section{References}

[1] V. Ficarra, G. Novara, W. Artibani et al., "Retropubic, laparoscopic, and robot-assisted radical prostatectomy: a systematic review and cumulative analysis of comparative studies," European Urology, vol. 55, no. 5, pp. 1037-1063, 2009.

[2] S. P. Elliott, J. W. McAninch, T. Chi, S. M. Doyle, and V. A. Master, "Management of severe urethral complications of prostate cancer therapy," Journal of Urology, vol. 176, no. 6, part 1, pp. 2508-2513, 2006.

[3] H. M. Joshi, D Vimalachandran, R. M. Heath, and P. S. Rooney, "Management of iatrogenic recto-urethral fistula by transanal rectal flap advancement," Colorectal Disease. In press.

[4] P. C. Walsh and A. W. Partin, "Anatomic radical retropubic prostatectomy," in Campbell-Walsh Urology, Saunders Elsevier, Philadelphia, Pa, USA, 9th edition, 2006.

[5] L. E. Harpster, F. M. Rommel, P. R. Sieber et al., "The incidence and management of rectal injury associated with radical prostatectomy in a community based urology practice," Journal of Urology, vol. 154, no. 4, pp. 1435-1438, 1995.

[6] F. Aguilo Lucia, J. F. Suarez Novo, J. Planes Morin, and E. Condom Mundo, "Radical prostatectomy. A review of our serie between 1997-2003," Actas Urologicas Espanolas, vol. 29, no. 6, pp. 542-549, 2005.

[7] J. A. Portillo Martin, M. Rado Velazquez, J. L. Gutierrez Banos et al., "Complications in a consecutive series of 133 cases of radical prostatectomy," Actas Urologicas Espanolas, vol. 25, no. 8, pp. 559-566, 2001.

[8] J. Noldus, S. Fernandez, and H. Huland, "Rectourinary fistula repair using the Latzko technique," Journal of Urology, vol. 161, no. 5, pp. 1518-1520, 1999.

[9] C. Thomas, J. Jones, W. Jäger, C. Hampel, J. W. Thüroff, and R. Gillitzer, "Incidence, clinical symptoms and management of rectourethral fistulas after radical prostatectomy," Journal of Urology, vol. 183, no. 2, pp. 608-612, 2010.

[10] F. dal Moro, M. Mancini, F. Pinto, N. Zanovello, P. F. Bassi, and F. Pagano, "Successful repair of latrogenic rectourinary fistulas using the posterior sagittal transrectal approach (YorkMason): 15-year experience," World Journal of Surgery, vol. 30, no. 1, pp. 107-113, 2006.

[11] W. Artibani, G. Grosso, G. Novara et al., "Is laparoscopic radical prostatectomy better than traditional retropubic radical prostatectomy? An analysis of peri-operative morbidity in two contemporary series in Italy," European Urology, vol. 44, no. 4, pp. 401-406, 2003.

[12] M. Remzi, H. C. Klingler, M. V. Tinzl et al., "Morbidity of laparoscopic extraperitoneal versus transperitoneal radical prostatectomy verus open retropubic radical prostatectomy," European Urology, vol. 48, no. 1, pp. 83-89, 2005.

[13] J. A. Brown, D. Rodin, B. Lee, and D. M. Dahl, "Transperitoneal versus extraperitoneal approach to laparoscopic radical prostatectomy: an assessment of 156 cases," Urology, vol. 65, no. 2, pp. 320-324, 2005.
[14] G. Guazzoni, A. Cestari, R. Naspro et al., "Intra- and peri-operative outcomes comparing radical retropubic and laparoscopic radical prostatectomy: results from a prospective, randomised, single-surgeon study," European Urology, vol. 50, no. 1, pp. 98-104, 2006.

[15] A. Jurczok, M. Zacharias, S. Wagner, A. Hamza, and P. Fornara, "Prospective non-randomized evaluation of four mediators of the systemic response after extraperitoneal laparoscopic and open retropubic radical prostatectomy," British Journal of Urology International, vol. 99, no. 6, pp. 1461-1466, 2007.

[16] J. Rassweiler, O. Seemann, M. Schulze, D. Teber, M. Hatzinger, and T. Frede, "Laparoscopic versus open radical prostatectomy: a comparative study at a single institution," Journal of Urology, vol. 169, no. 5, pp. 1689-1693, 2003.

[17] L. Salomon, O. Levrel, A. de la Taille et al., "Radical prostatectomy by the retropubic, perineal and laparoscopic approach: 12 years of experience in one center," European Urology, vol. 42, no. 2, pp. 104-111, 2002.

[18] M. Menon, A. Tewari, B. Baize, B. Guillonneau, and G. Vallancien, "Prospective comparison of radical retropubic prostatectomy and robot-assisted anatomic prostatectomy: the Vattikuti Urology Institute experience," Urology, vol. 60, no. 5, pp. 864-868, 2002.

[19] B. Nelson, M. Kaufman, G. Broughton et al., "Comparison of length of hospital stay between radical retropubic prostatectomy and robotic assisted laparoscopic prostatectomy," Journal of Urology, vol. 177, no. 3, pp. 929-931, 2007.

[20] A. Tewari, A. Srivasatava, and M. Menon, "A prospective comparison of radical retropubic and robot-assisted prostatectomy: experience in one institution," British Journal of Urology International, vol. 92, no. 3, pp. 205-210, 2003.

[21] J. C. Hu, R. A. Nelson, T. G. Wilson et al., "Perioperative complications of laparoscopic and robotic assisted laparoscopic radical prostatectomy," Journal of Urology, vol. 175, no. 2, pp. 541-546, 2006.

[22] B. Brehmer, H. Borchers, R. Kirschner-Hermanns, S. Biesterfeld, and G. Jakse, "Perioperative morbidity of the extended radical perineal prostatectomy," European Urology, vol. 40, no. 2, pp. 139-143, 2001.

[23] R. P. Gibbons, R. J. Correa Jr., G. E. Brannen, and J. T. Mason, "Total prostatectomy for localized prostatic cancer," Journal of Urology, vol. 131, no. 1, pp. 73-76, 1984.

[24] S. A. Fengler and H. Abcarian, "The York Mason approach to repair of iatrogenic rectourinary fistulae," American Journal of Surgery, vol. 173, no. 3, pp. 213-217, 1997.

[25] M. Kimura, V. Mouraviev, M. Tsivian, J. M. Mayes, T. Satoh, and T. J. Polascik, "Current salvage methods for recurrent prostate cancer after failure of primary radiotherapy," British Journal of Urology International, vol. 105, no. 2, pp. 191-201, 2010.

[26] B. R. Lane, D. E. Stein, F. H. Remzi, S. A. Strong, V. W. Fazio, and K. W. Angermeier, "Management of radiotherapy induced rectourethral fistula," Journal of Urology, vol. 175, no. 4, pp. 1382-1388, 2006.

[27] K. L. Chrouser, B. C. Leibovich, S. D. Sweat et al., "Urinary fistulas following external radiation or permanent brachytherapy for the treatment of prostate cancer," Journal of Urology, vol. 173, no. 6, pp. 1953-1957, 2005.

[28] G. T. Gotto, L. H. Yunis, K. Vora, J. A. Eastham, P. T. Scardino, and F. Rabbani, "Impact of prior prostate radiation on complications after radical prostatectomy," Journal of Urology, vol. 184 , no. 1 , pp. 136-142, 2010. 
[29] D. C. N. K. Nyam and J. H. Pemberton, "Management of iatrogenic rectourethral fistula," Diseases of the Colon and Rectum, vol. 42, no. 8, pp. 994-999, 1999.

[30] G. Gupta, S. Kumar, N. S. Kekre, and G. Gopalakrishnan, "Surgical management of rectourethral fistula," Urology, vol. 71, no. 2, pp. 267-271, 2008.

[31] D. Y. Pushkar, N. M. Sumerova, and G. R. Kasyan, "Management of urethrovaginal fistulae," Current Opinion in Urology, vol. 18 , no. 4, pp. 389-394, 2008.

[32] J. L. Faucheron, R. Rosso, E. Tiret et al., "Soave's procedure: the final sphincter-saving solution for iatrogenic rectal lesions," British Journal of Surgery, vol. 85, no. 7, pp. 962-964, 1998.

[33] T. E. Garofalo, C. P. Delaney, S. M. Jones, F. H. Remzi, and V. W. Fazio, "Rectal advancement flap repair of rectourethral fistula: a 20-year experience," Diseases of the Colon and Rectum, vol. 46, no. 6, pp. 762-769, 2003.

[34] M. Onaitis, K. Ludwig, A. Perez-Tamayo et al., "The Kraske procedure: a critical analysis of a surgical approach for midrectal lesions," Journal of Surgical Oncology, vol. 94, no. 3, pp. 194-202, 2006.

[35] T. D. Renschler and R. G. Middleton, "30 years of experience with York-Mason repair of recto-urinary fistulas," Journal of Urology, vol. 170, no. 4, part 1, pp. 1222-1225, 2003.

[36] M. Pera, S. Alonso, D. Parés et al., "Treatment of a rectourethral fistula after radical prostatectomy by York Mason posterior trans-sphincter exposure," Cirugia Espanola, vol. 84, no. 6, pp. 323-327, 2008.

[37] A. Crippa, M. F. Dall'Oglio, L. J. Nesrallah, E. Hasegawa, A. A. Antunes, and M. Srougi, "The York-Mason technique for recto-urethral fistulas," Clinics, vol. 62, no. 6, pp. 699-704, 2007.

[38] G. Dafnis, Y. H. Wang, and L. Borck, "Transsphincteric repair of rectourethral fistulas following laparoscopic radical prostatectomy," International Journal of Urology, vol. 11, no. 11, pp. 1047-1049, 2004.

[39] R. P. Boushey, R. S. McLeod, and Z. Cohen, "Surgical management of acquired rectourethral fistula, emphasizing the posterior approach," Canadian Journal of Surgery, vol. 41, no. 3, pp. 241-244, 1998.

[40] A. Kasraeian, F. Rozet, X. Cathelineau, E. Barret, M. Galiano, and G. Vallancien, "Modified York-Mason technique for repair of iatrogenic rectourinary fistula: the montsouris experience," Journal of Urology, vol. 181, no. 3, pp. 1178-1183, 2009.

[41] M. Spahn, D. Vergho, and H. Riedmiller, "Iatrogenic rectourethral fistula: perineal repair and buccal mucosa interposition," British Journal of Urology International, vol. 103, no. 2, pp. 242-246, 2009.

[42] O. Zmora, H. Tulchinsky, E. Gur, G. Goldman, J. M. Klausner, and M. Rabau, "Gracilis muscle transposition for fistulas between the rectum and urethra or vagina," Diseases of the Colon and Rectum, vol. 49, no. 9, pp. 1316-1321, 2006.

[43] R. Rivera, P. G. Barboglio, M. Hellinger, and A. E. Gousse, "Staging rectourinary fistulas to guide surgical treatment," Journal of Urology, vol. 177, no. 2, pp. 586-588, 2007.

[44] G. Ghoniem, M. Elmissiry, E. Weiss, C. Langford, H. Abdelwahab, and S. Wexner, "Transperineal repair of complex rectourethral fistula using gracilis muscle flap interpositioncan urinary and bowel functions be preserved?" Journal of Urology, vol. 179, no. 5, pp. 1882-1886, 2008.

[45] D. Ulrich, J. Roos, G. Jakse, and N. Pallua, "Gracilis muscle interposition for the treatment of recto-urethral and rectovaginal fistulas: a retrospective analysis of 35 cases," Journal of Plastic, Reconstructive and Aesthetic Surgery, vol. 62, no. 3, pp. 352-356, 2009.
[46] D. J. Culkin and C. E. Ramsey, "Urethrorectal fistula: transanal, transsphincteric approach with locally based pedicle interposition flaps," Journal of Urology, vol. 169, no. 6, pp. 2181-2183, 2003.

[47] J. E. Quazza, F. Firmin, and J. P. Cossa, "Recto-urethral fistula following prostatectomy: surgical repair using a combined perineal and laparoscopic approach. Procedure and results of two cases," Progres en Urologie, vol. 19, no. 6, pp. 434-437, 2009.

[48] A. H. Youssef, M. Fath-Alla, and A. W. El-Kassaby, "Perineal subcutaneous dartos pedicled flap as a new technique for repairing urethrorectal fistula," Journal of Urology, vol. 161, no. 5, pp. 1498-1500, 1999.

[49] B. C. Visser, J. W. McAninch, and M. L. Welton, "Rectourethral fistulae: the perineal approach," Journal of the American College of Surgeons, vol. 195, no. 1, pp. 138-143, 2002.

[50] D. M. Bochove-Overgaauw, H. P. Beerlage, K. Bosscha, and W. A. H. Gelderman, "Transanal endoscopic microsurgery for correction of rectourethral fistulae," Journal of Endourology, vol. 20, no. 12, pp. 1087-1090, 2006.

[51] M. Quinlan, R. Cahill, F. Keane, R. Grainger, and M. Butler, "Transanal endoscopic microsurgical repair of iatrogenic recto-urethral fistula," Surgeon, vol. 3, no. 6, pp. 416-417, 2005.

[52] D. M. Wilbert, G. Buess, and K. H. Bichler, "Combined endoscopic closure of rectourethral fistula," Journal of Urology, vol. 155, no. 1, pp. 256-258, 1996.

[53] F. Hata, T. Yasoshima, S. Kitagawa et al., "Transanal repair of rectourethral fistula after a radical retropubic prostatectomy: report of a case," Surgery Today, vol. 32, no. 2, pp. 170-173, 2002.

[54] R. Sotelo, A. Garcia, H. Yaime et al., "Laparoscopic rectovesical fistula repair," Journal of Endourology, vol. 19, no. 6, pp. 603606, 2005.

[55] R. Sotelo, R. de Andrade, O. Carmona et al., "Robotic repair of rectovesical fistula resulting from open radical prostatectomy," Urology, vol. 72, no. 6, pp. 1344-1346, 2008.

[56] M. A. Abdalla, "Posterior sagittal pararectal approach with rectal mobilization for repair of rectourethral fistula: an alternative approach," Urology, vol. 73, no. 5, pp. 1110-1114, 2009.

[57] O. A. Castillo, E. M. Bodden, G. J. Vitagliano, and R. Gomez, "Anterior transanal, transsphincteric sagittal approach for fistula repair secondary to laparoscopic radical prostatectomy: a simple and effective technique," Urology, vol. 68, no. 1, pp. 198-201, 2006.

[58] M. Chirica, Y. Parc, E. Tiret, N. Dehni, D. McNamara, and R. Parc, "Coloanal sleeve anastomosis (Soave procedure): the ultimate treatment option for complex rectourinary fistulas," Diseases of the Colon and Rectum, vol. 49, no. 9, pp. 1379-1383, 2006.

[59] M. L. Tancer, "Observations on prevention and management of vesicovaginal fistula after total hysterectomy," Surgery Gynecology and Obstetrics, vol. 175, no. 6, pp. 501-506, 1992.

[60] A. J. Vanni, J. C. Buckley, and L. N. Zinman, "Management of surgical and radiation induced rectourethral fistulas with an interposition muscle flap and selective buccal mucosal onlay graft," Journal of Urology, vol. 184, no. 6, pp. 2400-2404, 2010.

[61] R. Sotelo, M. Mirandolino, G. Trujillo et al., "Laparoscopic repair of rectourethral fistulas after prostate surgery," Urology, vol. 70, no. 3, pp. 515-518, 2007.

[62] V. Verriello, M. Altomare, G. Masiello, C. Curatolo, G. Balacco, and D. F. Altomare, "Treatment of post-prostatectomy 
rectourethral fistula with fibrin sealant (Quixil ${ }^{\mathrm{TM}}$ ) injection: a novel application," Techniques in Coloproctology, pp. 1-3, 2010.

[63] L. Patrlj, B. Kocman, M. Martinac et al., "Fibrin glueantibiotic mixture in the treatment of anal fistulae: experience with 69 cases," Digestive Surgery, vol. 17, no. 1, pp. 77-80, 2000.

[64] J. J. Park, J. R. Cintron, C. P. Orsay et al., "Repair of chronic anorectal fistulae using commercial fibrin sealant," Archives of Surgery, vol. 135, no. 2, pp. 166-169, 2000.

[65] D. F. Altomare, V. J. Greco, N. Tricomi et al., "Seton or glue for trans-sphincteric anal fistulae: a prospective randomized crossover clinical trial," Colorectal Disease, vol. 13, no. 1, pp. 82-86, 2011.

[66] F. Bardari, L. D’Urso, and G. Muto, "Conservative treatment of iatrogenic urinary fistulas: the value of cyanoacrylic glue," Urology, vol. 58, no. 6, pp. 1046-1048, 2001.

[67] Y. Bhandari, A. Khandkar, A. Chaudhary, P. Srimali, D. Desai, and V. Srinivas, "Post-radical prostatectomy rectourethral fistula: endosopic management," Urologia Internationalis, vol. 81, no. 4, pp. 474-476, 2008.

[68] F. Soave, "A new surgical technique for treatment of Hirschsprung's disease," Surgery, vol. 56, pp. 1007-1014, 1964. 


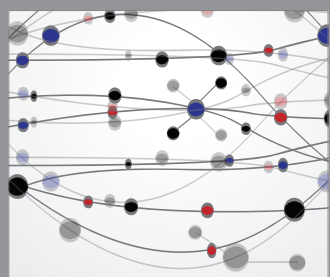

The Scientific World Journal
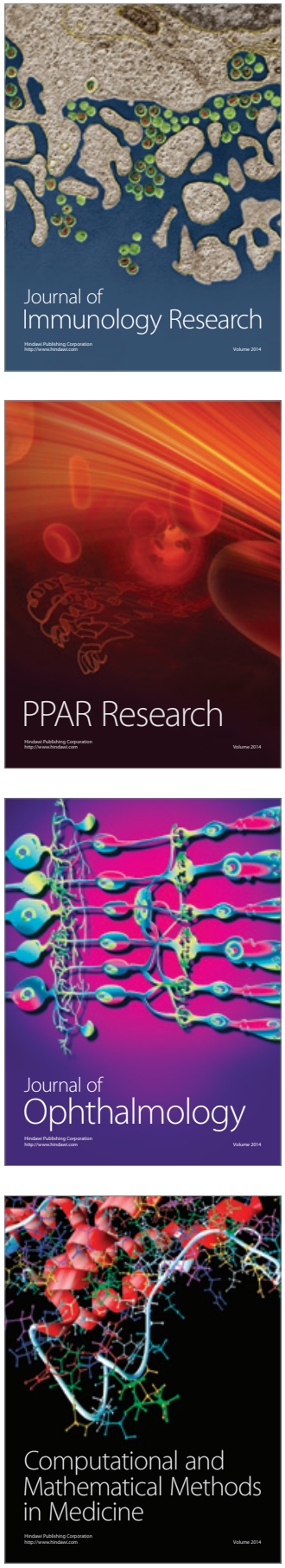

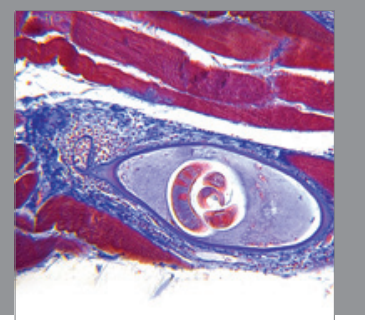

Gastroenterology

Research and Practice
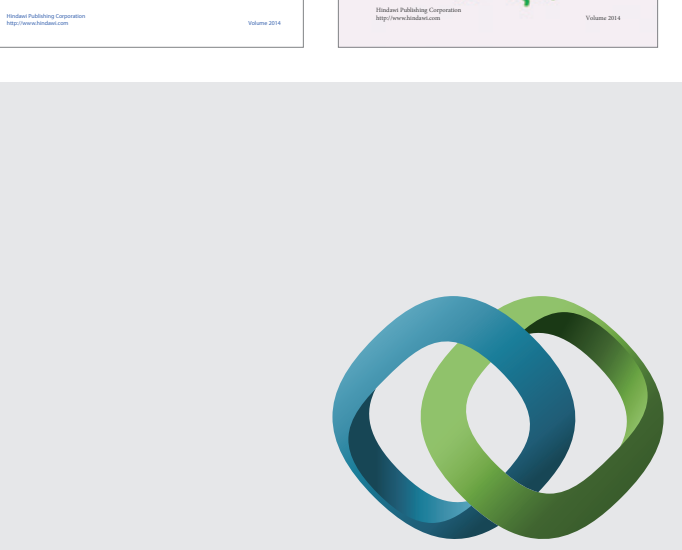

\section{Hindawi}

Submit your manuscripts at

http://www.hindawi.com
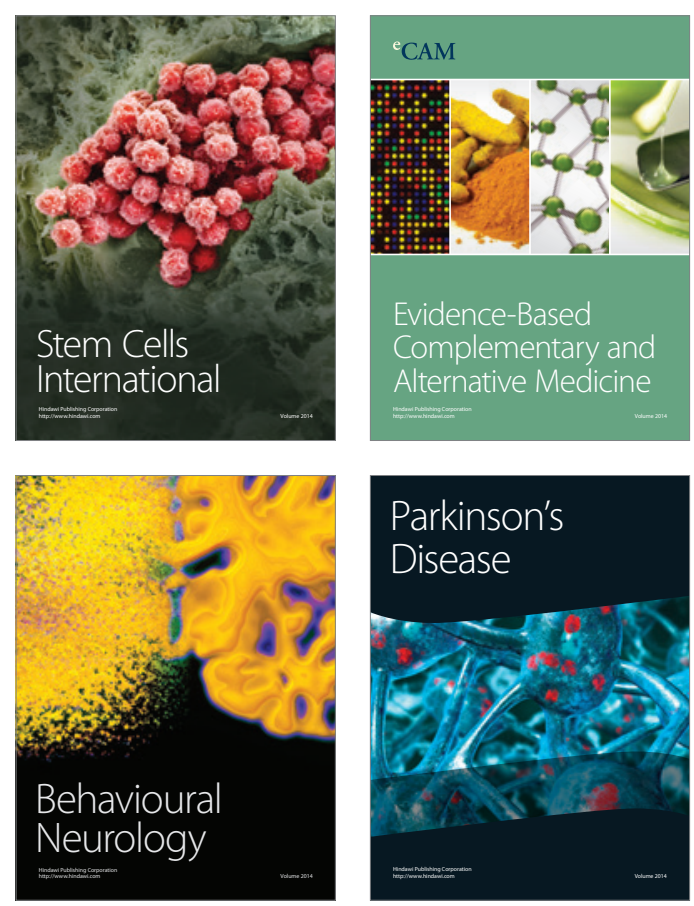

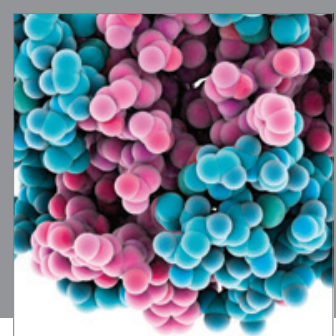

Journal of
Diabetes Research

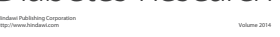

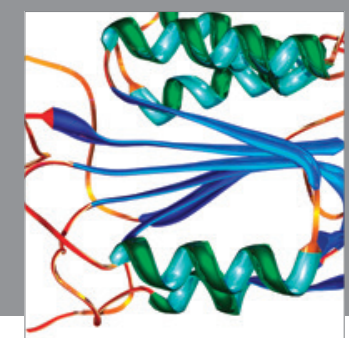

Disease Markers
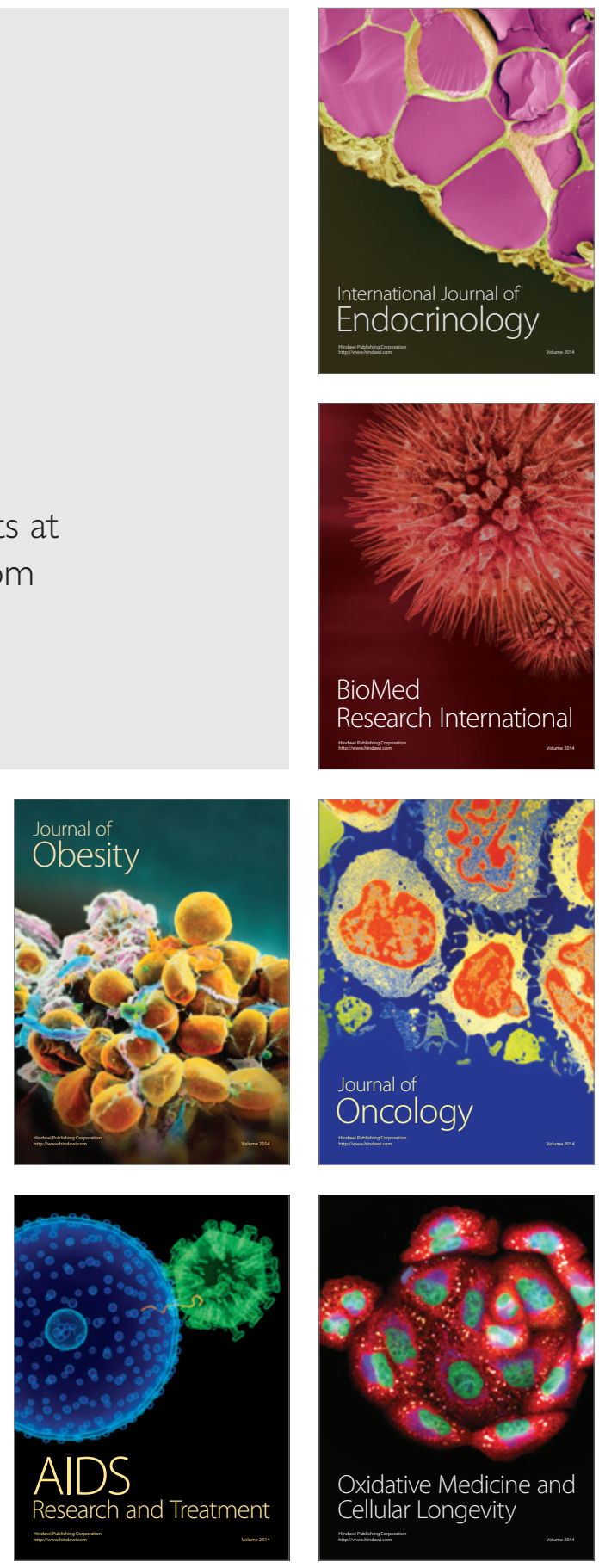